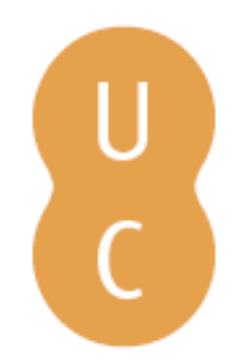

\title{
pompalina
}

\section{A Formação de educadores de jovens e adultos: dialogando com concepções} freireanas

\author{
Autor(es): Dantas, Tânia Regina \\ Publicado por: Imprensa da Universidade de Coimbra \\ URL \\ persistente: URI:http://hdl.handle.net/10316.2/41313 \\ DOI: $\quad$ DOl:https://doi.org/10.14195/978989 26 1326-0_24 \\ Accessed : $\quad$ 26-Apr-2023 13:48:01
}

A navegação consulta e descarregamento dos títulos inseridos nas Bibliotecas Digitais UC Digitalis, UC Pombalina e UC Impactum, pressupõem a aceitação plena e sem reservas dos Termos e Condições de Uso destas Bibliotecas Digitais, disponíveis em https://digitalis.uc.pt/pt-pt/termos.

Conforme exposto nos referidos Termos e Condições de Uso, o descarregamento de títulos de acesso restrito requer uma licença válida de autorização devendo o utilizador aceder ao(s) documento(s) a partir de um endereço de IP da instituição detentora da supramencionada licença.

Ao utilizador é apenas permitido o descarregamento para uso pessoal, pelo que o emprego do(s) título(s) descarregado(s) para outro fim, designadamente comercial, carece de autorização do respetivo autor ou editor da obra.

Na medida em que todas as obras da UC Digitalis se encontram protegidas pelo Código do Direito de Autor e Direitos Conexos e demais legislação aplicável, toda a cópia, parcial ou total, deste documento, nos casos em que é legalmente admitida, deverá conter ou fazer-se acompanhar por este aviso.

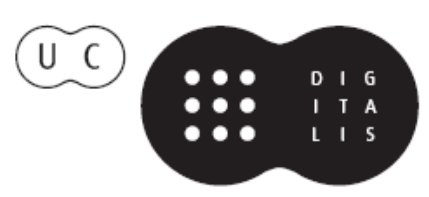




\section{A FORMAÇÃO DE EDUCADORES DE JOVENS EADULTOS: DIALOGANDO COM CONCEPÇÕ ES F R E I R E A N A S}

Tânia Regina Dantas ${ }^{126}$

\section{Resumo}

Este artigo tenciona contribuir para a compreensão do cenário atual acerca da formação dos educadores de jovens e adultos no Brasil e na Bahia. Destaca a importância desta formação para atender às demandas da sociedade contemporânea. Tendo como eixo fundante a pedagogia de Paulo Freire, resgata a contribuição deste educador para a educação de jovens e adultos. Este trabalho tem como objetivo principal a realização de um estudo preliminar com bases teóricas e metodológicas para conhecer a prática do educador de adultos, visando identificar as suas principais características e propor novas estratégias para a sua formação e a sua atuação na prática sócio-educativa. Tem como objetivo secundário apresentar as características principais do Programa de Pós-Graduação em Educação de Jovens e Adultos como uma ação pioneira no campo da EJA, no estado da Bahia. Comenta também a especificidade da educação de adultos a qual vem

126 Coord. do Mestrado Profissional em EJA; Docente da UNEB/Bahia /Brasil 
adquirindo relativa importância e se constituindo em um direito social dos sujeitos sociais. Entretece uma breve comparação entre os Mestrados Acadêmicos e os Mestrados Profissionais destacando o caráter inovador do Mestrado em EJA. Em culminância do artigo apresenta os desafios a serem enfrentados e as perspectivas do Programa de Pós-Graduação em EJA que estão sendo projetadas para o próximo biênio.

\section{Abstract}

This paper intends to contribute to the understanding of the current situation regarding teacher education in the context of youth and adult education in Brazil, particularly in Bahia. It highlights the importance of this kind of education to fulfill the demands of contemporary society. Taking Paulo Freire's pedagogy as a fundamental axis, this paper rescues the contribution of this author to youth and adult education. Therefore, the main objective of this paper is to report a preliminary study which addressed adult educators' practice in order to identify the main characteristics of this practice and to propose new strategies for their training and for their role in the socio-educative practice. A secondary objective is to present the main characteristics of the Post-Graduation Program in Youth and Adult Education as a pioneering effort in the field of youth and adult education in the state of Bahia. The text also remarks the specificity of adult education, which has been gaining relative importance and constituting a social right of social individuals. Besides, the reflection of this text develops a brief comparison between the Academic and the Professional Masters, stressing the innovative character of the Master in Youth and Adult Education. Finally, this article presents challenges to be faced and the prospects of the Post-Graduation Program in Youth and Adult Education that are being designing to the next two years. 


\section{Introdução}

A intenção deste trabalho será a de apresentar um breve panorama acerca da formação do educador a partir de contribuições de vários autores que vêm pesquisando sobre este tema, estabelecendo um paralelo com a formação do educador de adultos, tentando-se fazer uma contraposição das suas concepções e destacar a importância da qualificação dos professores de jovens e adultos e os saberes da experiência relacionados com experiências concretas de educadores e gestores que atuam ou pretendem atuar em programas de educação de jovens e adultos.

As constantes discussões sobre a formação docente nos levaram a questionar: como é que esta formação está sendo proposta no interior de um programa de pós-graduação que traz entre os seus objetivos centrais o de formar o professorado para trabalhar com a educação de jovens e adultos?

Entendemos que a formação integra a reflexão crítica, permite a colocação de problemas e questões que são comuns, facilita a troca de experiências e a busca constante de novas estratégias, novos métodos, novos recursos, melhorando a intervenção dos formadores/ pesquisadores e reformulando a prática docente a partir de um novo prisma.

Embasados em Freire alertamos que a formação é um fazer permanentemente que se refaz constantemente na ação, nunca se dá por mera acumulação de conhecimentos, é uma conquista mediante muitas ajudas provenientes de diversos agentes como professores, de materiais didáticos (livros, revistas), das aulas, das redes sociais, das trocas entre colegas, da experiência refletida e compartilhada. (Dantas, 2009).

Devemos partir da consideração de que não existe uma formação específica, obrigatória, a cargo das universidades, para o educador de jovens e adultos, efetuando-se uma formação inicial generalista 
em nível de segundo grau, nos cursos de Magistério, e uma formação continuada para quem atua na modalidade de educação de jovens e adultos (EJA) na educação básica, a cargo das secretarias municipais e estaduais de educação, que tomam como referência as Diretrizes Nacionais para o Ensino Fundamental e Ensino Médio e as Diretrizes Curriculares Nacionais para a Formação de Professores, promulgadas pelo Ministério de Educação.

Reforçando esta constatação, o Parecer 11/2000 do Conselho Nacional de Educação, aprovado pela Câmera de Educação Básica, que é um dos textos que regulamentam as Diretrizes Curriculares para a Educação de Jovens e Adultos, recomenda (no item VIII) que a formação docente deve ser uma formação continuada em serviço, voltada para a complexidade diferencial desta modalidade de ensino, sob a forma de curso de especialização, em nível de pós-graduação, como um aperfeiçoamento profissional em uma determinada área de conhecimento.

Neste sentido, este trabalho objetiva a realização de um estudo preliminar com bases teóricas e metodológicas para conhecer a prática do educador de adultos, visando identificar as suas principais características e propor novas estratégias para a sua formação e a sua atuação na prática sócio-educativa. Tem também como objetivo apresentar as características principais do Programa de Pós-Graduação em Educação de Jovens e Adultos como uma ação pioneira no campo da EJA, no estado da Bahia, destinada a qualificar o profissional desta modalidade. Destaca a disciplina que estuda e discute a obra do grande educador Paulo Freire como eixo fundante de toda a grade curricular do Mestrado Profissional.

Propõe uma reflexão sobre a formação de professores e, como nos ensinava Nóvoa (1995) pretende utilizar resultados de investigação que "apontam para a necessidade de aprofundar o conhecimento das estratégias e procedimentos de formação de professores, numa perspectiva que supere as práticas actuais 
[...]" (p. 65), como se sabe, são mais pautadas na intuição e na experiência do professor do que nos conhecimentos científicos acumulados pela humanidade.

A guisa de (in) conclusão estabelece uma breve comparação entre os Mestrados Profissionais e os Acadêmicos, apresenta os desafios que estão sendo enfrentados pelo programa de pós-graduação em EJA, como ainda as perspectivas de futuro que estão norteando o trabalho da equipe de professores e da equipe gestora.

\section{Na busca de outras trajetórias}

A formação dos professores no Brasil é uma temática que vem sendo defendida há anos pelas universidades, instituições e associações da categoria docente, debatendo-se, entre outros temas, a produção coletiva do conhecimento, os caminhos e as estratégias para melhorar esta formação, as políticas públicas desenvolvidas nesta área, as tendências das pesquisas mais recentes.

Imbernón (2001) vem salientando a necessidade da formação permanente do professorado como uma condição para o desenvolvimento profissional, levando-se em conta a evolução e o progresso das ciências, as mudanças sociais e culturais, como podemos observar neste trecho, a seguir:

En el ámbito educativo, ampliamente considerado, es ya un lugar común destacar la necesidad de la formación permanente del profesorado de todos los niveles, necesidad que se justifica sobre todo por la evolución y el progreso de las ciencias (y por supuesto aquí incluyo las de la educación), los cambios sociales y culturales, el cuestionamiento continuo y la obsolescencia de los contenidos de la enseñanza y el desarrollo profesional de los profesores en el sistema educativo. (Imbernón, 2001, p.7) 
A formação de professores em Educação de Jovens e Adultos (EJA) no Brasil vem sendo tratada nos seus fóruns estaduais e regionais específicos, nos Seminários Nacionais de Formação de Educadores de Jovens e Adultos, nos Encontros Nacionais sobre Educação de Jovens e Adultos (ENEJAS), nos Encontros Regionais sobre Educação de Jovens e Adultos (EREJAS). Está sendo discutido também em Reuniões Científicas da Associação Nacional de Pós-Graduação e Pesquisa em Educação (ANPED), como ocorreu em 2014, em Natal, onde a temática foi contemplada em uma Mesa Temática na qual se discutiu políticas públicas para inclusão, contrapondo a EJA com a educação do campo, indígena e educação popular.

A promoção de seminários nacionais, regionais, encontros, fóruns sobre a educação de jovens e adultos no Brasil vem revelando a preocupação dos órgãos públicos e das organizações da sociedade civil, notadamente das universidades, dos Fóruns estaduais e regionais, das secretarias de educação (estaduais e municipais), do próprio Ministério de Educação, de algumas organizações não governamentais, das associações de professores demonstrando que a EJA vem recebendo atenção especial no que concerne à formação de professores.

Resgatar a história da educação de jovens e adultos mediante a releitura das leis demonstra claramente que os cursos de formação inicial e continuada de professores sempre foram direcionados para uma teoria dissociada da prática, o que vem resultando numa formação precária e fragilizada, sendo este o grande desafio do momento atual que inclui a superação da desarticulação entre teoria e prática.

É comum a oferta de cursos de formação de professores pelos órgãos públicos sem o conhecimento das demandas e necessidades dos educadores de jovens e adultos, que clamam por uma qualificação adequada, como ainda de dispositivos para o enfrentamento dos grandes problemas que se deparam nas suas salas de aula.

Apesar de sua grande relevância social, a educação de adultos ainda não se constitui em uma prioridade nas sociedades da 
pós-modernidade, estando, historicamente, sempre vinculada à emergência e às mudanças das políticas sociais, quase sempre denominadas de compensatórias, assemelhadas com as campanhas esporádicas de alfabetização de adultos, envolvendo pessoas sem a devida qualificação que vêm atuando como voluntários em campanhas de alfabetização de adultos, como estagiários, bolsistas com contratos provisórios em programas esporádicos do governo destinados aos segmentos marginalizados da população, os excluídos da sociedade, como vem acontecendo nos programas de EJA propostos pelo governo federal ou estadual.

Os problemas enfrentados pelos professores vão desde a absoluta falta de recursos destinados especificamente a este segmento educacional, passando pela formação inadequada do professorado, a carência de material didático apropriado para o trabalho com adultos, chegando até à inexistência de uma política pública voltada especialmente para atender aos interesses da clientela que procura a educação de adultos e às necessidades formativas dos docentes.

Outro elemento importante a ser considerado é que a formação do educador de EJA nem sempre antecede ao trabalho em uma prática docente, uma vez que na maioria das vezes, o educador de jovens e adultos já atua há certo tempo numa prática efetiva e só depois é que procura se aperfeiçoar ou ressignificar a sua prática, mediante cursos de graduação ou de pós-graduação, em encontros, seminários, em processos de formação, etc. Também ocorre que a convocação de formadores em EJA nem sempre prioriza quem já tem prática docente, pois que muitos destes formadores atuam como voluntários ou prestadores de serviço, mediante contratação temporária, com baixa remuneração e condições de trabalho bem precárias, o que não contribui para atrair profissionais mais qualificados e mais experientes (Dantas, 2009).

A desvalorização do profissional da educação em EJA acompanha e reflete a desvalorização da própria EJA, pois que estes educado- 
res, além de terem contratos temporários, condições precárias de trabalho, salários irrisórios e ainda estão sendo considerados "invisíveis" para o sistema de ensino, como presas fáceis para serem manipulados pela política partidária.

O professor precisa ser requalificado como profissional e como protagonista, também melhorar as suas condições objetivas de trabalho, conseguir eliminar ou, pelo menos, diminuir o controle técnico, assumir o seu papel de mediador e de intelectual transformador (como nos fala Giroux, 1997), devendo ser crítico, fortalecer a sua autonomia como docente, priorizar o trabalho em equipe, compartilhar as suas experiências com os seus colegas e os seus alunos, reforçar a autonomia do grupo e, acima de tudo, valorizar a sua própria prática. Especialmente o professor da EJA precisa ser mais valorizado, necessita ser visto como alguém que detém saberes construídos a partir de sua própria prática, como sujeito consumidor e produtor de teoria e que pode intervir decisivamente na formulação de políticas públicas, sobretudo, nas políticas de formação do educador.

O lugar da formação deve ser um "lócus" de reflexão crítica sobre as práticas. Diante desta premissa, torna-se mais do que necessário investir na formação dos educadores de jovens e adultos e em professores que queiram enveredar no ensino e/ou na pesquisa neste campo de conhecimento. Arroyo (2002) confirmava esta necessidade quando afirmou que faz parte da reconfiguração da educação a necessidade emergente de se constituir "um corpo de profissionais educadores(as) formados(as) com competências específicas para dar conta das especificidades do direito à educação na juventude e na vida adulta” (p.21). Defende, portanto o direito à educação por parte dos jovens e adultos como prioridade básica.

A Resolução $n^{\circ}$ 3/2010 do CNE/CEB que instituiu as Diretrizes Operacionais para a EJA dizia que: [...] "cabe a institucionalização de um sistema educacional público de Educação Básica de Jovens e 
Adultos, como política pública de Estado e não apenas de governo, assumindo a gestão democrática, contemplando a diversidade de sujeitos aprendizes [...]". É preciso considerar também que uma das características definidoras do educador de adultos é a sua heterogeneidade como destaca Garcia Carrasco (1997) e que, portanto não se pode pensar e planejar num processo único e homogêneo de formação, já que existe uma multiplicidade de profissionais que vêm atuando na EJA.

É preciso considerar também a especificidade da educação de adultos a qual vem adquirindo relativa importância e se constituindo em um direito social. Nesta direção, Haddad \& Di Pierro (1999) enfatizam que a educação de adultos sempre compreendeu um conjunto bastante diversificado de processos e práticas formais e informais relacionadas com a aquisição e/ou a ampliação de conhecimentos básicos, de competências técnicas e profissionais, ou de habilidades sócio-culturais, desenvolvendo-se estes processos em escolas, em ambientes fora da escola, como na família, nos sindicatos, no trabalho, na igreja, em instituições religiosas outras, em espaços de lazer, e, atualmente, em redes sociais.

Reafirmando esta especificidade, Soares (2002) ressaltava que "o preparo de um docente voltado para a EJA deve incluir, além das exigências formativas para todo e qualquer professor, aquelas relativas à complexidade diferencial desta modalidade de ensino" (p. 18).

Ventura (2012) nos chama a atenção para se reconhecer a especificidade dos alunos da EJA que "não podem ser separados das suas condições de vida e das relações de poder na qual estiveram e estão mergulhados" (p. 76). Os alunos da EJA precisam ter reconhecida a sua diversidade cultural, as suas diferenças e peculiaridades, sendo considerados sujeitos/atores sociais, construtores de sua própria história. Com esta preocupação temos que levar em conta o risco de se criar propostas em EJA puramente bancárias como ela nos alerta e já nos alertava Freire, desconsiderando o lugar ocupado 
pelos alunos nas relações sociais e sem considerar as suas leituras de mundo e concepções de sociedade.

A criação do programa de pós-graduação em educação de jovens e adultos, em nível de Mestrado Profissional, vem dar uma decisiva contribuição a esta área de ensino e a este campo de investigação, proporcionando o fortalecimento da pesquisa educacional, a articulação entre o ensino, a pesquisa e a extensão, bem como a ampliação do estudo e da produção científica na área, visando melhorar a qualidade do ensino de graduação e de pós-graduação, como também a formação de professores sob a responsabilidade da Universidade do Estado da Bahia (UNEB).

O curso adotou como objetivo geral a qualificação profissional de recursos humanos com capacidade científica, didático-pedagógica, técnica, política, e ética para atuar no ensino, na pesquisa, na extensão e na gestão na área da educação de jovens e adultos, atendendo às peculiaridades desse campo e aos novos paradigmas educacionais para esta área.

Expressando as temáticas e os eixos formativos que compõem as suas linhas de pesquisa, o Mestrado Profissional em EJA se estrutura em três Áreas de Concentração que são: Educação, Trabalho e Meio Ambiente; Formação de Professores e Políticas Públicas; Gestão Educacional e Novas Tecnologias. Estas áreas constitutivas que desembocam nas linhas de pesquisa que vão orientar a elaboração dos projetos/propostas de pesquisa dos alunos estão sintonizadas com as implicações da pedagogia freireana com o meio ambiente, as questões relacionadas com o trabalho, a formação dos educadores e as políticas públicas, para quem a educação é eminentemente um ato político.

Não se poderia deixar de reconhecer a grande contribuição do educador Paulo Freire na valorização e no resgate da pessoa do professor ao defender uma pedagogia da autonomia e uma pedagogia da libertação, onde ele chama para uma reflexão sobre os 
saberes necessários a uma prática educativo-crítica e ao preconizar uma educação voltada para a emancipação do homem (Freire, 1999 e 1981). Este legado de Freire permanece fortemente vivo até hoje na prática pedagógica dos professores de EJA, sendo resgatado em processos de formação inicial e continuada, como também em cursos na pós-graduação.

Nesta direção, na proposta do curso em nível de Mestrado Profissional faz parte um Componente Curricular denominado Fundamentos teóricos e metodológicos da concepção freireana de educação que evidencia a importância das ideias de Paulo Freire sobre a educação frente ao contexto atual, analisando aspectos políticos, econômicos e sociais face às desigualdades sociais e históricas. Resgata as principais ideias, implicações e influência de diversos teóricos para Paulo Freire através do estudo, da análise e discussão de suas principais obras antes e depois do exílio. Discute também os diferentes conceitos e interpretações das concepções freireanas nas relações entre educação/meio ambiente, sociedade contemporânea, trabalho, compreensão de realidade e práxis educativa neste componente e em outros componentes da grade curricular.

Trata-se de uma proposta dialógica, como nos ensinava Paulo Freire (1999), na perspectiva de que só há diálogo com um profundo amor ao mundo e aos homens, com humildade sincera e mediante a fé no poder de criar do homem. É um ato de criação e recriação, de coragem e de compromisso, de valentia e de liberdade.

Intencionamos através do Plano de Ensino apresentado e discutido com os alunos do Mestrado desenvolver as seguintes habilidades e competências:

- Ampliação da autonomia e habilidade investigativa dos alunos mediante as suas propostas e projetos desenvolvidos no curso no campo da EJA, com as contribuições de conceitos e concepções freireanas; 
- Apresentação de domínio da concepção freireana e articular possibilidades de pesquisa sobre temáticas relevantes para a conjuntura atual;

- Realização de descobertas e achados importantes acerca dos objetos de investigação do alunado do Mestrado Profissional em EJA;

- Adoção de posicionamentos críticos, distinguindo concepções ingênuas para a sua superação;

- Reflexão em torno das políticas e possibilidades para a EJA com visão crítica e desalienadora. (Dantas \& Oliveira, 2014).

A proposta educativa incentiva a autonomia considerada como um princípio fundante pois, segundo Freire (1996) "o respeito à autonomia e à dignidade de cada um é um imperativo ético e não um favor que podemos ou não conceder uns aos outros"(p.66) . Desta forma, para ele a autonomia deve ser vista como um processo é um vir a ser. Por isso uma pedagogia da autonomia, respaldada na ética e, portanto, no respeito à dignidade humana, tem que estar centrada em experiências estimuladoras que incentivem a decisão e a responsabilidade, potencializando a própria autonomia dos educandos.

Esta disciplina, ministrada pelas professoras Tânia Regina Dantas e Maria Olívia Matos de Oliveira, docentes do Mestrado Profissional, vem contando com a colaboração de professores doutores do Instituto Paulo Freire, de professores da Universidade Estadual do Pará, da Universidade Federal de Santa Catarina, de coordenadores de Núcleos de Referência, de Grupos de Pesquisa em EJA e de outros programas que trabalham com a concepção freireana de educação com a realização de palestras, rodas de conversas e discussões em grupo presencial e nas redes de pesquisa. 


\section{Enfrentando os desafios e anunciando as perspectivas}

Os Mestrados Profissionais vêm-se afirmando no cenário da pós-graduação como propostas inovadoras que intencionam oferecer uma formação especializada em serviço, diferenciando-se por alguns termos sintéticos e simplificados que Paolo Nosella (2005) nos apresenta em contraponto aos Mestrados Acadêmicos, a saber:

1) é um curso com conteúdos mais práticos e específicos;

2) seu quadro docente é "predominantemente" de doutores;

3) em vez de dissertação, exige-se um trabalbo final (TCC);

4) possui uma "vocação para o auto-financiamento";

5) será avaliado pela CAPES que atribuirá as mesmas notas (1 a 7) utilizadas no Mestrado Acadêmico, para o credenciamento. (p.1)

Estas propostas de mestrados profissionais vêm encontrando muita receptividade junto aos professores que atuam na educação básica. A formação de professores da rede pública da Educação Básica está demandando a inclusão de estudos, teorizações e investigações dos professores acerca de problemas e desafios de sua realidade imediata, devendo priorizar a sua própria prática profissional. As disciplinas e atividades curriculares do Mestrado Profissional poderiam dar suporte a esse processo de formação mediado pelo estudo e investigação da prática profissional. Isso pressupõe implicações no sentido de construir inter-relações entre as práticas formativas dos formadores/docentes da universidade e as demandas das práticas profissionais dos professores.

Concordamos com Popkewitz (1995) quando defendeu a necessidade dos professores adquirirem maiores competências e exercitarem práticas de ensino com mais autonomia e responsabilidade, questionando padrões rígidos e estandardizados, o que 
implica diretamente no processo formativo dos professores, pois, segundo ele "as sociedades modernas exigem práticas de ensino que valorizem o pensamento crítico, a flexibilidade e a capacidade de questionar padrões sociais" (p.40).

Acreditando na concepção de que o professor é um intelectual e um estudioso de suas práticas e dos saberes que sustentam seu campo profissional, consideramos fundamental a pesquisa, sobretudo uma vez que, por meio dela, a relação entre teoria e prática se torna uma unidade dialética, que implica na realização de investigações sobre a prática profissional, para a produção de resultados que contribuam para transformar de maneira efetiva e qualificada a gestão escolar e as práticas de ensinar e aprender nas diferentes áreas de conhecimento.

Tendo a pesquisa como eixo da formação, está sendo exigido como trabalho de conclusão de curso (TCC) a produção de uma investigação sobre uma problemática específica voltada para a prática escolar, podendo o aluno também realizar uma dissertação, ou apresentar um projeto de pesquisa que seja viável a sua aplicação na comunidade onde ele está inserido.

O Mestrado Profissional em EJA está em consonância com estes critérios e princípios e foi criado para responder à demanda reprimida e a uma oferta dispersa, como salienta Flecha (1999), no campo da educação de jovens e adultos, visando formar e qualificar o professorado e gestores que atuam em EJA. Este coletivo, que se caracteriza pela sua heterogeneidade, como os demais professores, vem batalhando pela sua valorização e qualificação como profissionais em educação, tentando alcançar sua autonomia docente face às complexas relações sociais e profissionais que enfrenta no seu cotidiano.

Esta proposta vem trazendo importantes contribuições tanto para o desenvolvimento profissional dos docentes e discentes do curso, quanto para a melhoria da prática pedagógica, pois viabiliza a construção de conhecimentos e de uma cultura profissional da docência e da gestão escolar pelos próprios professores da 
educação básica, que são os alunos do curso de pós-graduação, tendo os formadores/docentes da Universidade como parceiros e colaboradores fundamentais desse processo educativo.

Para Ventura (2012) um dos grandes desafios que se coloca para a EJA seria "o reconhecimento da área como um campo diferenciado no âmbito da educação básica com características e possibilidades próprias" (pp.76-77).

Visando impulsionar este propósito e incrementar a investigação no campo da EJA, neste momento, os principais desafios do Programa de Pós-Graduação em Educação de Jovens e Adultos-MPEJA são os seguintes:

\section{DESAFIOS DO MPEJA}

- Colaborar para implantar uma política pública de estado para a EJA;

- Garantir a infraestrutura básica (espaço físico, recursos humanos, equipamentos, materiais permanentes e de consumo) para o pleno funcionamento do Programa;

- Desenvolver pesquisas com os estudantes do programa que tenham aplicabilidade e impacto nas comunidades;

- Articular ensino, pesquisa e extensão no âmbito das atividades desenvolvidas no programa;

- Captar recursos para garantir as ações e atividades planejadas para o biênio 2015-2016;

- Concretizar os convênios que estão em processo de negociação (IFBAIANO, IFBA, Secretaria de Educação do Estado e Secretaria Municipal de Lauro de Freitas);

- Publicar quatro livros com temáticas versando sobre EJA neste biênio envolvendo docentes e discentes do programa;

- Credenciar novos professores para ministrar as disciplinas do programa que necessitam de docentes; 
- Participar de outras Redes de pesquisa tanto em âmbito nacional como internacional;

- Realizar o II Encontro Internacional de Alfabetização e Educação de Jovens e Adultos;

- Compor as Bancas de Defesa dos Trabalhos de Conclusão de Curso para os 60 alunos do programa garantindo a participação de professores de outras instituições.

Precisamos levar em consideração que os alunos do Mestrado Profissional em EJA como sujeitos de aprendizagem e por estarem na condição de professores da educação básica podem constituir comunidades investigativas que produzem conhecimentos relacionados ao seu campo profissional e, para tanto, precisam adquirir competência para utilizar criticamente o saber acadêmico como instrumento de compreensão, problematização e transformação de suas práticas, de forma que teoria e prática sejam entretecidas e indissociáveis durante o seu percurso formativo.

Nesta direção, precisamos tecer relações, fortalecer parcerias em âmbito nacional e internacional, consolidar pesquisas em andamento, desenvolver estudos e propostas curriculares que atualizem permanentemente as práticas curriculares locais, interconectadas com as tendências nacionais e internacionais de inovação e atualização educacional na área da educação de jovens e adultos.

Para tanto, as Perspectivas do Programa de Pós-Graduação em EJA que estão sendo projetadas para o biênio 2015-2016 compreendem:

\section{Perspectivas do MPEJA}

Aumentar a nota para 4 na primeira avaliação trienal do Programa pela Coordenação de Aperfeiçoamento de Pessoal para o Ensino Superior - CAPES; 
Garantir a participação de docentes do MPEJA em eventos nacionais e internacionais;

Captar recursos para incrementar o projeto de estado da arte da pesquisa em EJA no Estado da Bahia nos últimos dez anos;

Realizar o Seminário Internacional sobre Direitos Humanos na UNEB em articulação com várias instituições promotoras;

Concluir as etapas finais do Convênio entre a UNEB em articulação com o Programa de Pós-Graduação em Educação de Jovens e Adultos - MPEJA e a Universidade do Minho, em Portugal, já assinado pelos Reitores das duas instituições;

Incrementar a produção científica do Programa com mais publicações no campo da EJA;

Finalizar a Parceria com a Rede Internacional de Pesquisa em Educação e Trabalho-RIET, com a Argentina para deslanchar projetos de pesquisa em colaboração acerca de temáticas que tangenciam questões relacionadas com trabalho, meio ambiente na educação de jovens e adultos.

Venho, juntamente com a equipe de docentes do Programa de Pós-Graduação apontando sugestões que assegurem a melhoria da qualidade da formação de professores, a utilização de novas alternativas metodológicas em processos formativos, visando atender às expectativas e demandas dos profissionais que trabalham com a educação de jovens e adultos.

O trabalho em colaboração certamente servirá para contribuir na instituição de uma política pública de estado que possibilite ações contínuas e afirmativas para mudar o cenário da EJA no estado da Bahia.

\section{In (conclusão)}

A formação em EJA é uma temática bastante discutida, mas está a demandar ações afirmativas para que os professores que atuam 
neste campo tenham uma qualificação que atenda às especificidades da modalidade da educação de jovens e adultos.

Perseguimos um sonho e a esperança de melhoria da formação de educadores com base em Freire, como nos incentiva em sua obra Pedagogia da Esperança (2001), ao dizer "[...] sem sequer poder negar a desesperança como algo concreto e sem desconhecer as raízes históricas, econômicas e sociais que a explicam, não entendo a existência humana e a necessária luta para fazê-la melhor, sem esperança e sem sonho" (p.10). Fica claro que caminhamos na direção de uma pedagogia da pertinência e da esperança, sem as quais a existência humana não faz sentido.

Este trabalho pedagógico, desenvolvido no programa de pós-graduação no campo da EJA, vem potencializando fomentar propostas de estudos e investigações junto com os alunos do curso, subsidiadas pelos fundamentos teóricos e metodológicos da pedagogia freireana na perspectiva de construção de conhecimentos e de configuração de novas práticas pautadas em posturas dialógicas.

Pretendemos impactar a educação nas comunidades nas quais os alunos se inserem mediante a realização de trabalhos de investigação que envolvam os professores e gestores da educação básica, tanto em âmbito municipal como em âmbito estadual, abrangendo diversas escolas públicas na capital e no interior baiano.

As contribuições esperadas pelo programa de pós-graduação em educação de jovens e adultos - MPEJA se inserem, sobretudo, em inovar linhas de investigação em educação, em aplicar pesquisas no campo da EJA, em abrir caminhos investigativos para outros pesquisadores, em ampliar as pesquisas acerca da formação de professores, em discutir e suscitar reflexões mais aprofundadas sobre a importância do educador de adultos na atualidade, em conhecer melhor as características marcantes deste educador.

Contribuirá, também em provocar o debate acerca da educação de adultos e suas modalidades de atuação, no Brasil e outros 
países do exterior mediante as redes de pesquisa associadas ao programa, a participação de docentes do programa em eventos internacionais, em instituição de parcerias interinstitucionais, apontando soluções e novas estratégias para a formação de educadores da EJA, que potencializem a melhoria da educação básica e que auxiliem a enfrentar os enormes desafios da formação de professores neste país.

\section{Referências bibliográficas}

Arroyo, M. (2002). Ofício de Mestre: imagens e auto-imagens. Petrópolis: Editora Vozes.

Conselho Nacional de Educação/Câmara de Educação Básica. (2000). Diretrizes Curriculares Nacionais para a Educação de Jovens e Adultos. Relator Conselheiro Carlos Jamil Cury. Parecer 11/2000. Brasília: CEB.

Dantas, T. (2009). Professores de adultos: formação, narrativa autobiográfica e identidade profissional. Tese de Doutorado (não publicada). Barcelona: Universidad Autónoma de Barcelona.

Dantas, T. \& Oliveira, M. (2014). Plano de Ensino. Disciplina Fundamentos Teóricos e Metodológicos da Concepção Freireana de Educação.(mimeo).

Flecha, R. (1999). Compartiendo palabras: el aprendizaje de las personas adultas através del diálogo. Barcelona: Ediciones Paidós Ibérica.

Freire, P. (1981). Ação cultural para a liberdade. Rio de Janeiro: Paz e Terra.

Freire, P. (1999). Pedagogia da Autonomia: saberes necessários à prática educativa. São Paulo: Paz e Terra.

Freire, P.. (2001). Pedagogia da Esperança. Um reencontro com a Pedagogia do oprimido. São Paulo: Paz e Terra.

Garcia Carrasco, J. ([Coord). (1997). Educación de adultos. Barcelona: Editorial Ariel.

Giroux, H. (1997). Os professores como intelectuais: rumo a uma pedagogia crítica da aprendizagem. Porto Alegre: Editora Artes Médicas Sul.

Haddad, S. \& Di Pierro, C. (1999). Satisfação das necessidades básicas de aprendizagem de jovens e adultos no Brasil: contribuições para uma avaliação da década da Educação para Todos. Texto subsidiário à exposição realizada no Seminário Nacional sobre Educação para todos: implementação de compromissos de Joimtem no Brasil. Brasília: MEC.

Imbernón, F. (2001). La formación del profesorado. Madrid: Paidós.

Nosella, P. (2005). Mestrado Profissional em Educação? São Carlos: UFSCar. (mimeo).

Nóvoa, A. (Coord.) (1995). Os professores e a sua formação. Lisboa: Publicações Dom Quixote. 
Popkewitz, T. (1995). Profissionalização e formação de professores: algumas notas sobre a sua história, ideologia e potencial. In A. Nóvoa (org.), Os professores e a sua formação (pp. 35-30). Lisboa: Publicações Dom Quixote.

Soares, L. (2002). Diretrizes Curriculares Nacionais. Educação de Jovens e Adultos. Rio de Janeiro: DP\&A Editora.

Ventura, J. (2012). A EJA e os desafios da formação docente nas licenciaturas. Revista da FAEEBA-Educação e Contemporaneidade, 21(37), 71-82. 